\author{
Н.Л. Козакова, В.І. Кузьменко \\ Дніпровський національний університет імені Олеся Гончара
}

\title{
ОБЕРНЕНА ЗАДАЧА ВИЗНАЧЕННЯ МЕХАНІЧНИХ ХАРАКТЕРИСТИК ШАРУ ГІРСЬКОЇ ПОРОДИ
}

\begin{abstract}
Розглянута пружна ізотропна тришарова смуга, що знаходиться під дією власної ваги та нормального навантаження, яка має порожнину на другому шарі. Розв'язана обернена задача визначення густини матеріалу та модуля Юнга верхнього шару. Використано апарат варіаційних методів. Дискретизація виконана за допомогою методу скінченних елементів. Для розв'язання скінченновимірної задачі застосовано метод верхньої релаксації. Розв'язання оберненої задачі грунтусться на екстремальному формулюванні та методі локальних варіацій. Виконано аналіз практичної збіжності розроблених алгоритмів. Здійснена апостеріорна оцінка похибки розв'язання оберненої задачі.

Ключові слова: густина шару, модуль деформації, варіаційна постановка задачі, обернена задача, метод скінченних елементів, метод локальних варіацій.

\author{
N.L. Kozakova, V.I. Kuzmenko \\ Oles Honchar Dnipro National University
}

\section{THE INVERSE PROBLEM OF DEFINING THE MECHANICAL ROCK LAYER CHARACTERISTICS}

The strategy of research of general coefficient inverse problems in natural science, in mechanics in particular, is currently aimed at developing different approaches to the study of incorrect problems, to which inverse problems are reduced, at developing efficient numerical schemes combining direct methods, iterative schemes and regularization. In this paper, the problem of flat deformation of a rigid body is considered. An elastic isotropic three-layer strip is considered, which is under the action of its own weight and normal load, and has a cavity on the second layer. The inverse problem of determining the material density and Young's modulus of the upper layer is solved. The inverse problem is solved under the condition that the (measured) values of displacements are known on the upper surface of the cavity. The inverse problem is formulated in the extreme form of the search for Young's modulus and density from the condition of the minimum root-mean-square deviation, the calculated and measured values of the displacements at the points of the upper surface of the cavity. The method of local variations is used to solve the inverse problem. At each step of the local variation method, the direct problem of determining displacements is solved for a given Young's modulus and density. The apparatus of variational methods was used. Discretization is performed using the finite element method. The upper relaxation method is used to solve the finite-dimensional problem. For the obtained values of Young's modulus and density, the analysis of the stress-strain state. The solution of the inverse problem is based on the extreme formulation and the method of local variations. The analysis of the practical convergence of the developed algorithms is carried out. The a posteriori estimation of the error of the solution about the problem is carried out. The obtained results indicate a sufficient level of accuracy in determining the mechanical characteristics. The results can be used in the design of underground engineering structures.

(C) Козакова Н.Л., Кузьменко В.I., 2021 
Keywords: layer density, deformation modulus, variational problem statement, inverse problem, finite element method, method of local variations.

\author{
Н.Л. Козакова, В.И. Кузьменко \\ Днипровский национальный университет имени Олеся Гончара
}

\title{
ОБРАТНАЯ ЗАДАЧА ОПРЕДЕЛЕНИЯ МЕХАНИЧЕСКИХ ХАРАКТЕРИСТИК СЛОЯ ГОРНОЙ ПОРОДЫ
}

Рассмотрена упругая изотропная трехслойная полоса, которая находится под действием собственного веса и нормальной нагрузки, и имеет полость на втором слое. Решена обратная задача определения плотности материала и модуля Юнга верхнего слоя. Использован аппарат вариационных методов. Дискретизация выполнена с помощью метода конечных элементов. Для решения конечномерной задачи применен метод верхней релаксации. Решение обратной задачи основывается на экстремальной формулировке и методе локальных вариаций. Выполнен анализ практической сходимости разработанных алгоритмов. Осуществлена апостериорная оценка погрешности решения обратной задачи.

Ключевые слова: плотность слоя, модуль деформации, вариационная постановка задачи, обратная задача, метод конечных элементов, метод локальных вариаций.

Вступ. Стратегія дослідження загальних коефіцієнтних обернених задач в природознавстві, в механіці зокрема, в даний час спрямована на розробку різних підходів до вивчення нелінійних некоректних проблем, до яких зводяться обернені задачі, на розробку ефективних чисельних схем, що поєднують прямі методи, ітераційні схеми і регуляризацію в тій чи іншій формі [1-9]. У статті [1] представлені основні постановки і методи дослідження коефіцієнтних обернених задач. Наведено класифікацію таких в залежності від реконструйованих об'єктів. Виділено три класи задач: скінченномірні, задачі про визначення одновимірних функцій та про відновлення багатовимірних законів. Обговорено основні підходи при дослідженні обернених задач кожного типу. У роботі [2] визначення модуля Юнга для неоднорідної за глибиною смуги грунтується на експериментальній діаграмі вдавлювання штампу у поверхню смуги.

Постановка задачі. Розглядається задача плоскої деформації твердого тіла. Нехай переріз багатошарового тіла, нескінченного у напрямку нормалі до площини $x_{1} O x_{2}$ (рис.1), що займає плоску область, яка складається 3 трьох шарів та на глибині $h_{1}$, має порожнину 3 розмірами $2 l \times h_{2}$. Пружні шари мають густину $\rho_{i}, i=\overline{1,3}$. Бічні поверхні та поверхня порожнини вільні від напружень. Шари зчеплені між собою, нижня поверхня - 3 жорсткою основою.

Смуга деформується під дією власної ваги та нормально розподіленого навантаження:

$$
\tilde{q}\left(x_{1}\right)=\left\{\begin{array}{lll}
-q, & \text { якщо } & -a \leq x_{1} \leq a, \\
0, & \text { якщо } & x_{1}<-a, x_{1}>a
\end{array}\right.
$$


Система шуканих функцій складається із компонент векторів напружень $\{\sigma\}=\left\{\sigma_{11}, \sigma_{12}, \sigma_{12}\right\}, \quad$ переміщень $\{u\}=\left\{u_{1}, u_{2}\right\} \quad$ та деформацій $\{\varepsilon\}=\left\{\varepsilon_{11}, \varepsilon_{12}, \varepsilon_{12}\right\}$ в точках області $\Omega$ :

$$
\begin{aligned}
\Omega=\bigcup_{k=1}^{3} \Omega^{(k)}, \Omega^{(1)}=\left\{\left(x_{1}, x_{2}\right), x_{1} \in[-L,+L], x_{2} \in\left[-h_{1}, 0\right],\right\}, \\
\Omega^{(2)}=\left\{\left(x_{1}, x_{2}\right), x_{1} \in[-L,+L], x_{2} \in\left[-\left(h_{2}+h_{1}\right),-h_{1}\right]\right\}, \\
\Omega^{(3)}=\left\{\left(x_{1}, x_{2}\right), x_{1} \in[-L,+L], x_{2} \in\left[-\left(h_{3}+h_{2}+h_{1}\right),-\left(h_{2}+h_{1}\right)\right]\right\} .
\end{aligned}
$$

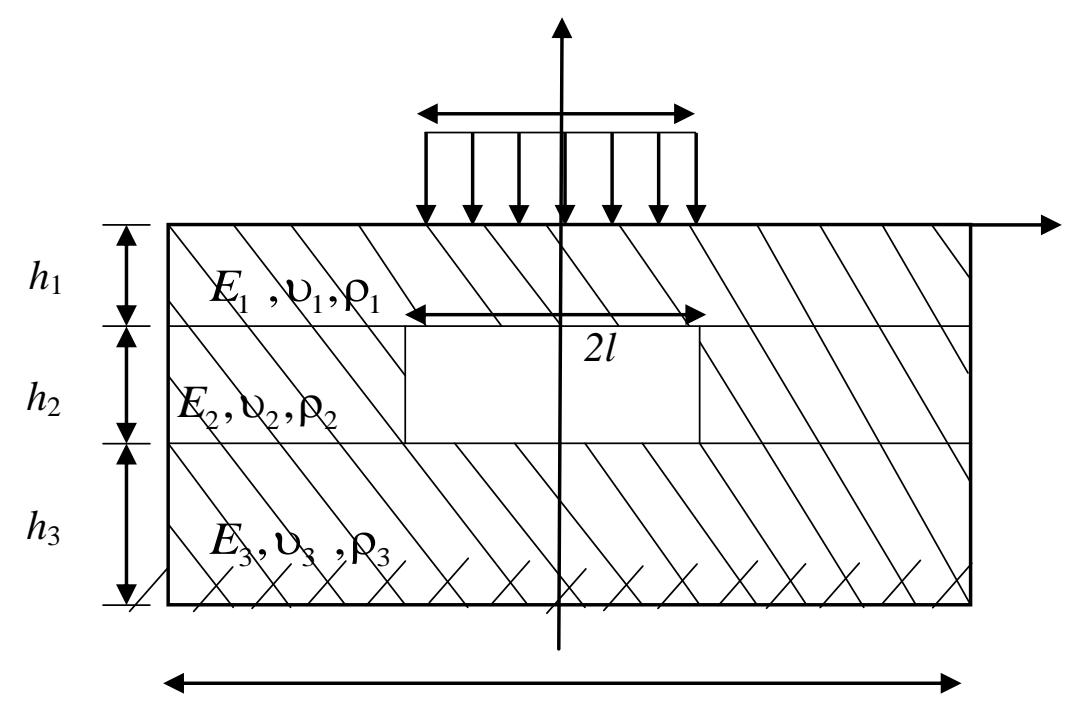

Рис. 1. Схема навантаження шарів

Ці функції повинні задовольняти рівняння рівноваги, співвідношення Коші, співвідношення закону Гука для пружного ізотропного тіла, а також вказані крайові умови.

Метод розв'язання прямої задачі. Крайовій задачі відповідає варіаційна постановка прямої задачі: необхідно знайти вектор $W^{*}=\left\{u_{1}^{*}, u_{2}^{*}\right\}$ такий, що

$$
W^{*}=\underset{W \in \bar{W}}{\arg \min } J_{\Pi}(W)
$$

Функціонал повної енергії системи має вигляд:

$$
\begin{aligned}
& J_{\Pi}(W)=\frac{1}{2} \iint_{\Omega}\left(\left\{\lambda\left(\frac{\partial u_{1}}{\partial x_{1}}+\frac{\partial u_{2}}{\partial x_{2}}\right)^{2}+2 \mu\left[\left(\frac{\partial u_{1}}{\partial x_{1}}\right)^{2}+\left(\frac{\partial u_{2}}{\partial x_{2}}\right)^{2}\right]+\right.\right. \\
& \left.\left.+\mu\left(\frac{\partial u_{1}}{\partial x_{2}}+\frac{\partial u_{2}}{\partial x_{1}}\right)^{2}\right\}+\rho g u_{2}\right) d x_{1} d x_{2}+\int_{-a}^{a} \tilde{q}\left(x_{1}\right) u_{2} d x_{1} .
\end{aligned}
$$

де $E$ - модуль пружності ізотропного матеріалу; $v$ - коефіцієнт Пуассона, $\lambda=\frac{v E}{(1+v)(1-2 v)}, \mu=G=\frac{E}{2(1+v)} ; \bar{W}$ - множина допустимих переміщень, які задають кінематичні крайові умови. 
Задачу (1) розв'язано методом скінченних елементів. Обрано прямокутні скінченні елементи. Було введено сітку з вузлами в точках 3 координатами $X_{s}=\left\{x_{1 s}, x_{2 s}\right\}, s=\overline{1, N}$. Тоді невідомі функції подаються у вигляді векторів, компонентами яких є значення функцій задачі в вузлах сітки:

$$
U=\left\{U_{i}\right\}^{T}, U_{i}=\left\{U_{i s}\right\}^{T}, \varepsilon_{i j}=\left\{E_{i j s}\right\}^{T}, \sigma=\left\{\sigma_{i j s}\right\}^{T}, i, j=1,2, s=\overline{1, N} .
$$

Після підстановки скінченно-елементної апроксимації в функціонал (2), виконання процедур інтегрування та варіювання отримаємо систему лінійних алгебраїчних рівнянь:

$$
K U=P,
$$

яка еквівалентна умові

$$
\frac{\partial \widetilde{J}_{\Pi}}{\partial U_{i s}}=0, i=1,2, s=\overline{1, N} ;
$$

$\tilde{J}_{\Pi}$ - значення функціоналу після підстановки скінченно-елементної апроксимації та виконання процедури інтегрування; $K$ - матриця жорсткості; $P$ - глобальний вектор вузлових сил.

Для розв'язання системи (3) використано метод верхньої релаксації.

Формулювання та метод розв'язання оберненої задачі. Нехай на верхній поверхні порожнини відомі (виміряні) значення переміщень $\hat{u}_{2}\left(x_{1}, h_{1}\right)$, $-l \leq x_{1} \leq l$. Необхідно знайти модуль пружності $E$ та густину $\rho$ матеріалу верхнього шару, за яких після вказаного навантаження переміщення верхньої поверхні порожнини збігаються з виміряними. Оскільки вимірювання містять неминучу похибку, то доцільно вимагати щоб обчислені переміщення були близькими до виміряних. Тому переходимо до екстремального формулювання оберненої задачі:

$$
V^{*}=\underset{V \in \bar{V}}{\arg \min } J(V)
$$

де $J(V)=\int_{-l}^{l}\left(u_{2}(V)-\hat{u}_{2}\right)^{2} d x_{1} ; \bar{V}=\{\bar{E}, \bar{\rho} \in D\} ; D-$ множина допустимих значень.

Сформульована задача розв'язується за допомогою методу локальних варіацій [6], на кожному кроці якого розв'язується пряма задача.

Аналіз числових результатів. Позначимо через $\bar{x}_{i}=x_{i} / a, \bar{u}_{i}=u \cdot \frac{E_{1}}{q}, \bar{\varepsilon}_{i j}=\varepsilon_{i j} \cdot \frac{E_{1} a}{q}, \bar{\sigma}_{i j}=\sigma_{i j} \cdot \frac{a}{q}, i, j=1,2$, безрозмірні значення координат, переміщень, деформацій та напружень відповідно.

Розрахунки були виконані для $\bar{l}=l / a=2.5, \bar{h}_{1}=h_{1} / a=1.875$, $\bar{h}_{2}=h_{2} / a=0.625, \bar{h}_{3}=h_{3} / a=2.1875$. Розрахунки виконані 3 використанням 747 скінченних елементів. 
Для розрахунку обрано: $q=300(H / M)$, константи матеріалу другого пружного шару - густина $\rho_{2}=17\left(\kappa H / \mathrm{M}^{3}\right)$, модуль Юнга $E_{2}=19(M П а)$ і коефіцієнт Пуассона $v_{2}=0.3$, пружної основи $-\rho_{3}=20\left(\kappa H / \mathrm{M}^{3}\right), E_{3}=37($ МПа $), v_{3}=0.4$.

Роботу та результати алгоритму методу локальних варіацій демонструє табл.1.

Було обрано такі початкові значення: $E=11(M П a), \rho=16,2\left(\kappa H / \mathrm{M}^{3}\right)$. Для отримання оптимального значення функції $J(E, \rho)$ було виконано 8 ітерацій.

Таблиия 1

Значення цільового функціонала $J(E, \rho)$

\begin{tabular}{|c|c|c|c|c|c|c|}
\hline $\begin{array}{c}E \\
\rho\end{array}$ & 9,0 & 11,0 & 13,0 & 15,0 & 17,0 & 19,0 \\
\hline 16,0 & & 7,18 & 2,22 & 0,379 & 0,00282 & \\
\hline 16,2 & 19,4 & 7,21 & 2,23 & 0,384 & 0,00252 & 0,333 \\
\hline 16,4 & & 7,24 & 2,24 & 0,388 & 0,00215 & 0,330 \\
\hline 16,6 & & & & 0,393 & 0,00184 & 0,326 \\
\hline 16,8 & & & & 0,399 & 0,00155 & 0,322 \\
\hline 17,0 & & & & 0,404 & 0,00128 & 0,000001 \\
\hline 17,2 & & & & & 0,00112 & \\
\hline
\end{tabular}

Обираємо як розв'язок задачі густину матеріалу $\rho=17\left(\kappa H / \mathrm{m}^{3}\right)$, модуль Юнга $E=19$ (МПа).

Для найдених значень розв'язку оберненої задачі проведено аналіз напружено-деформованого стану смуги. На рис. 2 - 4 подані графіки розподілу напружень $\bar{\sigma}_{i j}=\bar{\sigma}_{i j}\left(\bar{x}_{1}, \bar{h}_{1}\right)$, де $\bar{h}_{1}=1.75$. 


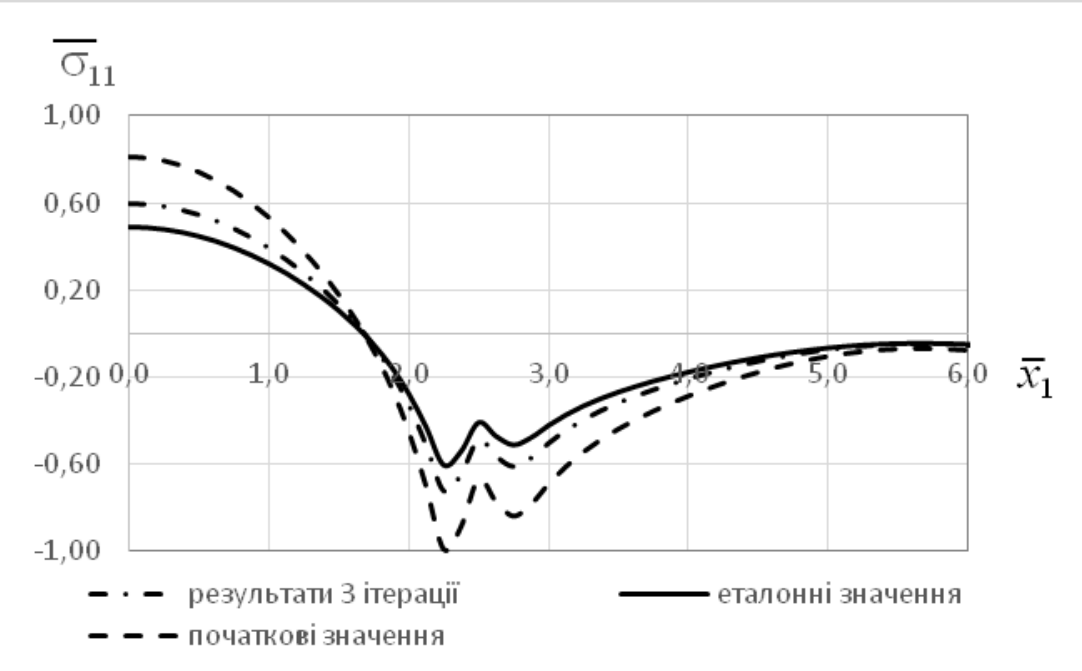

Рис. 2. Відносні напруження $\bar{\sigma}_{11}$

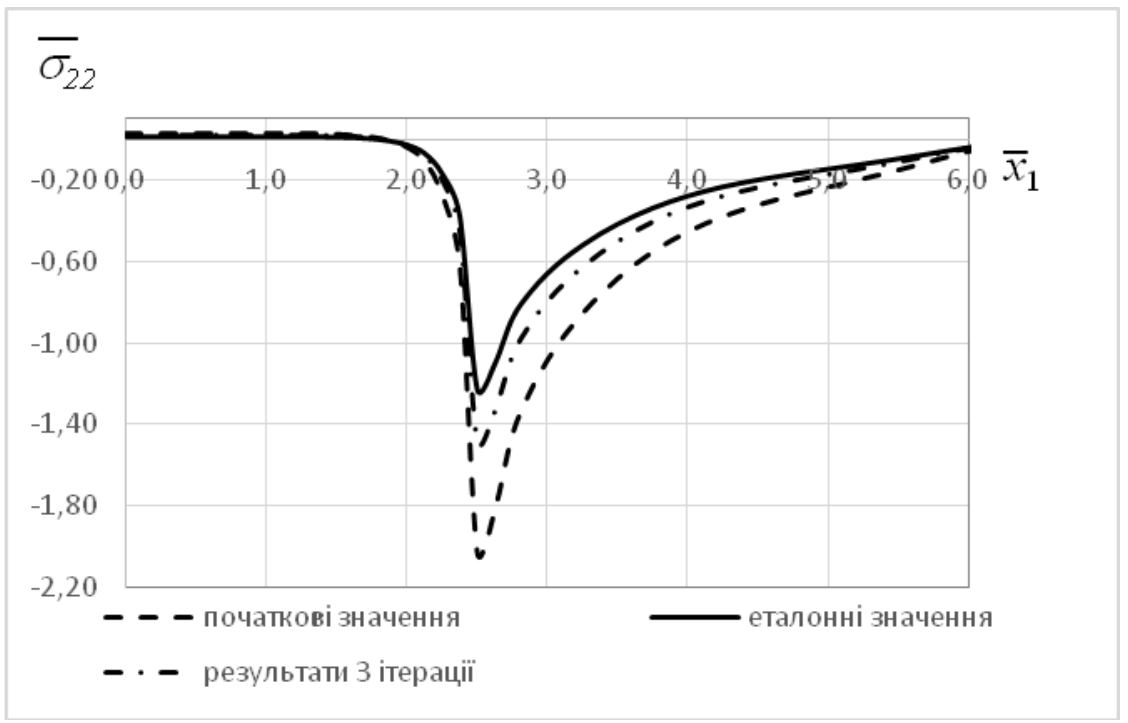

Рис. 3. Відносні напруження $\bar{\sigma}_{22}$

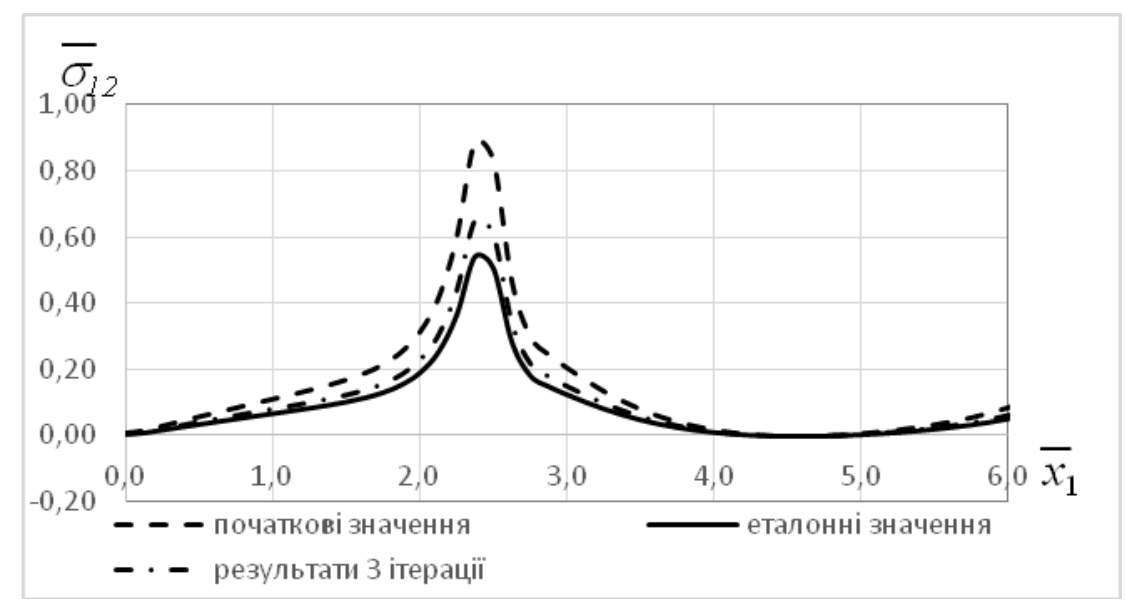

Рис. 4. Відносні напруження $\bar{\sigma}_{12}$

Максимальні напруження виникають в околі значення параметру $\bar{x}_{1}=2.5$. 
На рис. 5, 6 представлено процес збіжності значень компонент вектора переміщень $\bar{u}_{1}, \bar{u}_{2}$ до виміряних (еталонних) значень $\hat{u}_{1}, \hat{u}_{2}$ в залежності від початкового наближення і числа ітерацій.

Спостерігаємо, як функції переміщень із зростанням кількості ітерацій прямують до еталонних значень, що свідчить про коректність роботи алгоритму.

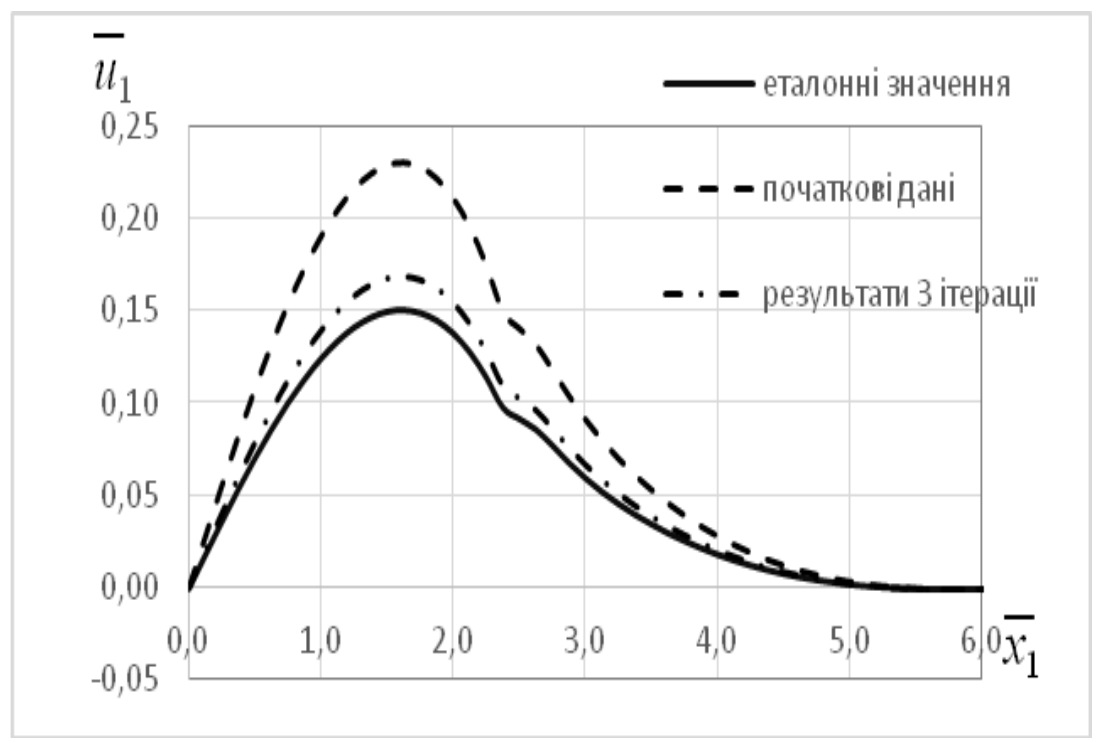

Рис. 5. Відносні нормальні переміщення точок

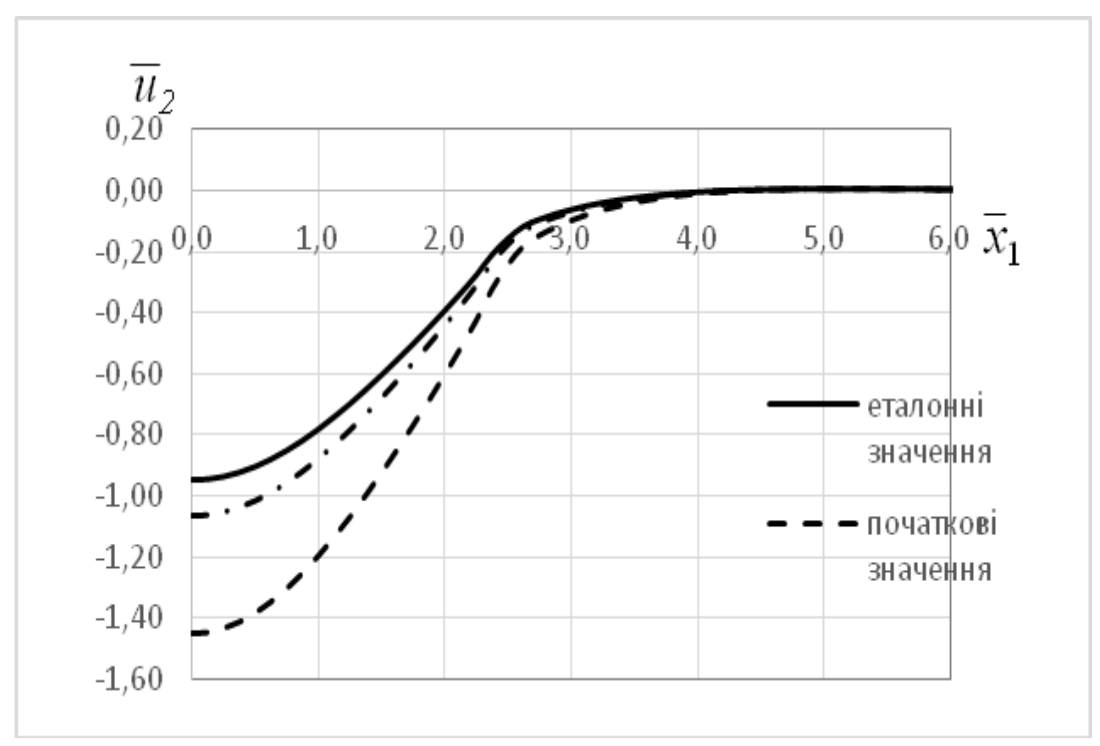

Рис. 6. Відносні дотичні переміщення точок

Висновки. Запропоновано підхід до розв'язання обернених задач відновлення модуля Юнга та густини матеріалу шару на основі експерименту вимірювання переміщень. Обернена задача формулюється у екстремальній формі. Отримані результати свідчать про достатній рівень точності визначення механічних характеристик. Результати можуть бути використані при проєктуванні підземних інженерних споруд. 


\section{Бібліографічні посилання}

1. Ватульян А.О., Плотников Д.К. Обратные коэффициентные задачи в механике. Вестник Пермского наи. исслед. политехн. ун-та. Механика. 2019. № 3. С. $37-47$.

2. Коваленко О.В., Кузьменко В.І. Обернена контактна задача для неоднорідного пружного тіла. Вісн. Дніпропетр. нац. ун-ту. Серія «Механіка». 2013. Вип.17. Т.2. C. 82-91.

3. Козачок О.П., Мартиняк Р.М., Слободян Б.С. Взаємодія тіл з регулярним рельєфом за наявності міжконтактного середовища. Львів: Растр-7, 2018. 200 с.

4. Лукашевич А.А., Розин Л.А. О решении контактных задач строительной механики с односторонними связями и трением методом пошагового анализа. Инж.-строит. журн. 2013. № 1. С. 75-81.

5. Прокопишин I.I., Мартиняк Р.М. Числове дослідження контактної взаємодії двох тіл 3 виїмкою методом декомпозиції області. Проблеми обчислювальної механіки і міцності конструкиій. 2011. № 16. С. 232-239.

6. Черноусько Ф.Л., Баннчук Н.В. Вариационные задачи механики и управления (Численные методы). Москва: Наука, 1973. 240 с.

7. Bal G. Introduction to Inverse Problems. New York: Columbia University, 2012. 205 p.

8. Bonnet M., Constantinescu A. Inverse problems in elasticity. Inverse Probl. 2005. № 21. P. $1-50$.

9. Neto F.D.M., Neto A.J.S. An Introduction to Inverse Problems with Applications. Berlin: Springer, 2013. $255 \mathrm{p}$.

Надійшла до редколегії 02.07. 2021. 